\title{
PROGRAMA AMIGA ÁRVORE: PLANTIO DE ÁRVORES EM VIAS PÚBLICAS NA CIDADE DE PIRACICABA/SP
}

José Hamilton de Aguirre Junior ${ }^{1}$, Andrea Volpe-Filik², Ana Maria Liner Pereira Lima ${ }^{3}$.

\section{RESUMO}

Piracicaba, cidade do interior paulista, com uma população de 366.442 habitantes, sofreu um processo intenso de retirada de Sibipirunas (Caesalpinia pluviosa DC.), espécie que predominava na arborização viária, sem a adequada reposição dos indivíduos suprimidos. Este trabalho expõe os dados coletados, em agosto e setembro de 2002, do Programa Amiga Árvore, realizado pela Prefeitura Municipal de Piracicaba, que atendeu 8 bairros da periferia: Paineiras, Piracicamirim, Paulista, Balbo, Costa Rica, Alvorada II e III e Água Branca. As espécies utilizadas foram as disponíveis no viveiro municipal. Os plantios foram feitos pelos funcionários da Prefeitura e com o auxílio das crianças e adolescentes do Programa Agente Jovem. Este trabalho possibilitou o plantio de 420 indivíduos, utilizando 23 espécies. Esta experiência foi, por um lado, positiva, ao integrar os jovens com a comunidade, preparando-os para trabalhos sócio-ambientais; por outro lado, mostrou-se negativa, ao plantar, preferencialmente, espécies arbustivas, que possuem funções ambientais inferiores às de um indivíduo arbóreo. Como principal objetivo, o trabalho visa alertar e levar à reflexão sobre o plantio prioritário de espécies arbustivas ou de pequeno porte nas vias públicas das cidades brasileiras e, da conseqüente redução dos benefícios que poderiam ser obtidos pela utilização de árvores.

Palavras-chave: arborização urbana, Programa Amiga Árvore, arbustos, benefícios.

\footnotetext{
${ }^{1}$ Engenheiro Florestal, mestrando USP/ESALQ, Piracicaba - SP, jhaguirr@gmail.com

2 Engenheira Agrônoma, doutoranda USP/ESALQ, Piracicaba - SP, avfilik@esalq.usp.br

${ }^{3}$ Engenheira Agrônoma, Professora Doutora USP/ESALQ, Piracicaba - SP, amlplima@esalq.usp.br
} 


\title{
PROGRAMA AMIGA ÁRVORE (TREE FRIEND PROGRAM): PLANTATION OF TREES AT PUBLIC SIDEWALKS IN THE CITY OF PIRACICABA/SP
}

\begin{abstract}
Piracicaba, a city located in the state of São Paulo (Brazil), with a population of 366.442 inhabitants, suffered an intense extract process of the Caesalpinia pluviosa DC. trees, the dominant species of the city's street arborization, without the correct replacement of the removed individuals. This work exposes the collected data in the period since August to September of 2002 in the "Programa Amiga Árvore" (Tree Friend Program) realized for the Piracicaba Municipal Mayor at 8 suburbian districts. The utilized species were the ones available at the municipal nursery. The plantation was made by the mayor's employees along with support of young people of the "Programa Agente Jovem" (Young Agent Program). This work was responsible for planting 420 trees distributed among 24 different species in 2 months. This experience was positive because it integrated young people with the community, which prepared them for social-environmental works; however, it was also negative considering the prefered utilization of shrub and small size tree species. This work intends to alert and induce reflection regarding the prefered planting of shrub and small size arboreal species at public streets of Brazilian cities and to prevent the consequent reduction on benefits that would be obtained by utilizing trees.
\end{abstract}

Key-words: urban arborization, Tree Friend Program, shrubs, benefits. 


\section{INTRODUÇÃO}

Piracicaba, cidade paulista e localizada a, aproximadamente, $170 \mathrm{~km}$ da capital, possui uma população de 366.442 habitantes (IBGE, 2006), 95\% dela concentrada na área urbana do município. Tinha na Sibipiruna, Caesalpinia pluviosa DC., a principal espécie utilizada na arborização viária de sua região central e entorno, representando 56,1\% do total de indivíduos desta área da cidade (LIMA, 1993). Ao longo do tempo, as Sibipirunas foram cortadas, por motivos como entupimento de calhas (pela queda e acúmulo de folíolos), levantamento de calçadas (por afloramento de raízes) e mortes dos indivíduos. A retirada destas árvores não teve a substituição necessária, gerando um grande déficit arbóreo e, a introdução de arbustos e árvores de pequeno porte aumentou a rejeição popular às árvores de espécies maiores, afetando, negativamente, o aspecto ambiental da cidade.

A partir da metade do século XX, o modelo de desenvolvimento brasileiro gerou uma urbanização acelerada, intensificando a disputa de espaços entre árvores e equipamentos públicos (MENEGHETTI, 2003). Uma maneira de achar que esse problema pudesse ser resolvido foi, durante muito tempo, e ainda o é, a escolha de árvores de pequeno porte para locais sob fiação, o que, para cidades de clima quente, deixa muito a desejar, em termos ecológicos e de qualidade de vida (PAIVA; GONÇALVES, 2002).

A maior parte da população brasileira está organizada em áreas urbanas (IBGE, 2007; SILVA FILHO, 2004). As cidades correspondem a maior alteração antropogênica do meio natural (LOMBARDO, 1985). A árvore é o elemento que melhora significativamente o ambiente urbano (PAIVA; GONÇALVES, 2002) e seu conjunto, nas cidades, exerce funções fundamentais para a manutenção da qualidade de vida, como por exemplo, reduzindo a amplitude térmica e amenizando o clima, diminuindo os ruídos, filtrando os poluentes, contendo enchentes e o escoamento superficial, ao reter a água das chuvas e ampliar a infiltração (SILVA FILHO, 2004; PAIVA; GONÇALVES, 2002).

O processo de intensa urbanização sem uma adequada revegetação, pode ser um dos formadores do processo já conhecido por "llhas de calor". Este fenômeno ocorre nas cidades, devido à grande concentração de áreas construídas e pavimentadas que favorecem a absorção de radiação solar durante o dia e a reflete à noite, gerando diferencial térmico entre o centro e as áreas periféricas mais vegetadas (LIMA, 1993). Árvores de médio e grande porte reduzem esses efeitos, por exemplo, ao transpirarem, aproximadamente, 380 litros de água por dia, o mesmo potencial resfriador de 5 aparelhos de ar condicionado médios (2500 kcal/h) funcionando durante 20 horas diariamente (GREY; DENEKE, 1978). A adequada arborização e uma boa ventilação são dois elementos fundamentais para que ocorra o conforto ambiental no clima tropical úmido (LIMA, 1993). 
O sombreamento da copa das árvores sobre o asfalto faz o calor diminuir, aumentando o conforto para os cidadãos (SILVA FILHO, 2007); tal sombreamento das árvores também permite a melhor conservação do asfalto, pela redução do impacto da água das chuvas e da volatilização de seus compostos pela exposição ao calor, reduzindo gastos públicos com a manutenção da pavimentação viária e ampliando sua vida útil (MCPHERSON; MUCHNICK, 2005). Baseando-se nessa pesquisa, Silva Filho (2006), calculou em $\mathrm{R} \$ 900.000,00$ a economia anual aos cofres públicos de Piracicaba, somente com o maior sombreamento arbóreo dos 18 milhões de $\mathrm{m}^{2}$ de vias públicas (asfaltadas) da cidade. A economia seria de $\mathrm{R} \$ 15,47$ por metro quadrado de asfalto/ano, atingindo $\mathrm{R} \$ 278.460 .000,00$ em 30 anos, que poderiam financiar a arborização da cidade.

Segundo a Associação Americana de Engenheiros Florestais, os benefícios proporcionados por cada árvore, como a economia de arrefecimento ou aquecimento, o controle da erosão e do escoamento superficial, a proteção à vida silvestre e o controle da poluição atmosférica, propiciam US\$273,00/indivíduo/ano (PAIVA; GONÇALVES, 2002), o que representa um grande patrimônio, com retorno financeiro garantido.

O planejamento da paisagem é uma necessidade e um desafio. Devido à degradação ambiental da atualidade, ocorre a maior necessidade de preservação e valorização dos elementos naturais, principalmente, nas cidades. A arborização urbana humaniza os espaços e, num país tropical como o Brasil, as árvores são muito importantes por sua capacidade de redução do calor excessivo, da incidência solar direta e de golpes de ventos (STRINGHETA, 2005). Os benefícios da arborização são tão mais necessários à saúde ambiental do ecossistema urbano, quanto maior for a sua urbanização (MENEGHETTI, 2003).

As árvores, no ambiente urbano, passam a sofrer impactos dos mais variados, desde solos totalmente adversos ao desenvolvimento das raízes, passando pela adaptação das copas aos espaços urbanos, através da poda de galhos, muitas vezes incompatível com o modelo arquitetônico natural da espécie, o que aumenta a probabilidade de acidentes (SEITZ, 2005).

Do ponto de vista social, para haver sucesso no planejamento da arborização urbana, o envolvimento da comunidade é essencial e sua participação é uma prática recomendável, como educação ambiental, para a mudança de atitudes, de comportamentos e de posturas contrárias ao plantio de árvores. Os órgãos públicos buscam parcerias para o desenvolvimento sustentável nas cidades e, a participação comunitária norteia esse desafio (SILVA, 2005).

Ao estudar a arborização viária da região central de Piracicaba e seu entorno, Lima (1993) elencou alguns dos maiores problemas existentes na cidade, destacando o grande número de indivíduos apresentando raízes que danificavam o calçamento (62,3\%), a região 
de área livre de solo, no colo das plantas insuficiente a seu desenvolvimento $(89,3 \%)$ e a presença de indivíduos podados (69,9\%). Outros fatores destacados foram a ausência de afastamento predial $(58,6 \%)$ ou presença de fiação aérea $(55,9 \%)$, plantas doentes $(10,5 \%)$ e praguejadas $(17,4 \%)$. Dentre as árvores vivas, na época, 4127 foram encontradas nas calçadas laterais, totalizando 108 espécies; a espécie predominante foi a Caesalpinia pluviosa DC. com $56,1 \%$ do total de indivíduos.

Ao longo do tempo, as Sibipirunas e outras árvores de maior porte foram cortadas, pela cidade, devido às inúmeras solicitações dos munícipes incomodados com a queda de folhas, entupimento de calhas e danificação de calçadas. Houve um processo de intensa retirada arbórea na região central de Piracicaba, sem a devida reposição; esta, quando ocorria, priorizava a utilização de espécies de porte reduzido, dentre muitos arbustos, com espécies de pouco ou nenhum caráter ambiental, principalmente devido à pouca área de copa e reduzido sombreamento de superfícies refletoras de calor. Nos novos plantios, destacou-se o uso de espécies como a falsa murta, a espirradeira, o cróton, o chapéu de napoleão, a grevílea anã e o hibisco, levando a "miniaturização" e "arbustificação" de muitas regiões outrora arborizadas da cidade e influenciando negativamente a visão dos moradores, que conduziram a escolha e o plantio de árvores de grande ou médio porte em frente a suas residências para arbustos e arvoretas, todas espécies de pequeno porte.

Arbustos são vegetais de estrutura lenhosa ou semi-lenhosa, com altura de 3 a 6 metros e ramificação desde sua base. Árvores possuem fuste único, lenhoso, sendo divididas pelo seu porte: pequeno, para aquelas com altura entre 4 a 6 metros e copa com diâmetro inferior a 4 metros; médio, quando suas alturas estiverem compreendidas entre 6 e 10 metros e, o diâmetro de suas copas, entre 6 a 10 metros; e grande, quando possuírem altura e diâmetro de copa superiores a 6 metros (MASCARÓ; MASCARÓ, 2005).

Nas regiões periféricas da cidade faltaram programas de arborização e, quando ocorriam, também utilizavam muitas espécies de pouco valor para o microclima urbano. Os fatos expostos geraram, ao longo do tempo, um déficit significativo de arborização pela cidade, aproximadamente 41 mil árvores em suas vias públicas (SILVA FILHO, 2007), o que, concomitantemente ao aumento de áreas impermeabilizadas, como conseqüência têm contribuído para a redução da qualidade de vida da população, em termos ambientais.

\section{MATERIAIS E MÉTODOS}

Como forma de reverter a carência em matéria de árvores na cidade, a Prefeitura Municipal de Piracicaba, por meio da SEDEMA (Secretaria Municipal de Defesa do Meio Ambiente) promoveu alguns projetos de arborização, dentre eles, o Programa denominado Amiga Árvore. No período de coleta exposto (agosto e setembro de 2002), referente a parte 
do estágio supervisionado do autor, realizou-se a arborização de 8 bairros periféricos recém asfaltados e/ou com grande demanda e necessidade de árvores, dentre os quais, Paineiras, Piracicamirim, Paulista, Balbo, Costa Rica, Alvorada II, Alvorada III e Água Branca. Dentre os critérios adotados, destacaram-se a escolha de espécies, de acordo com a largura da calçada, utilização de espécies de porte arbustivo ou pequeno no caso da presença de fiação, espaçamento adequado, espécies de interesse ornamental e que não prejudicassem a estrutura, as fundações e calhas das residências.

Incentivou-se a participação popular, através da escolha orientada de espécies, destacando, através de um catálogo fotográfico, características como sua floração, altura e folhas, de forma que o munícipe se sentisse envolvido, aumentando, assim, as chances de sucesso dos plantios realizados. Foram utilizadas espécies disponíveis no viveiro municipal de Piracicaba; para isso, confeccionou-se um folder explicativo sobre o plantio e houve a assinatura de um termo de compromisso pelo morador, em que ele autorizava o plantio a ser realizado e se comprometia a zelar pelo desenvolvimento da muda plantada em frente à sua residência (Figura 1).

Prefeitura do Glunicípio de Piracicaba

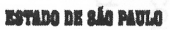

Secretaria Municipal de Defesa do Melo Ambiente e Planejamento

Programa:

Amiga Árvore

Amigo cidadão:

Nós da Sedema estamos iniciando um Programa de arborização de calçadas.

Serão plantadas árvores adequadas ao local, que não prejudicam a estrutura da casa, nem quebram a calçada, nem causam problemas à fiação. Ao contrário, essas árvores embelezam a cidade, e fornecem sombra, amenizam a temperatura, melhoram a umidade do ar, diminuem a poluição e abafam os ruídos, além de fornecerem pouso e até alimentos para os pássaros.

Se, em frente à sua casa, há espaço para plantar árvore e você pretende melhorar o meio ambiente, colabore plantando ou pedindo para plantar e cuidar dela.

A Sedema se responsabilizará por todo o processo de plantio, desde a abertura da cova até o fornecimento da muda.

Contamos com você.

Para falar com a Prefeitura, ligar no tel. - 430-1245 ou 430-1251.

Agradecemos,

$$
\begin{aligned}
& \text { Secretaria Municipal de Defesa do Meio } \\
& \text { Ambiente/Planejamento }
\end{aligned}
$$

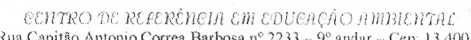

$$
\begin{aligned}
& \text { Rua Capitào Antonio Correa Barbosa no 22.33 - } 9^{\circ} \text { andar - Cep. } 13.400-900 \\
& \text { Telefone: (019) } 430-1252 \cdots \text { Fax (019) } 4.301255
\end{aligned}
$$

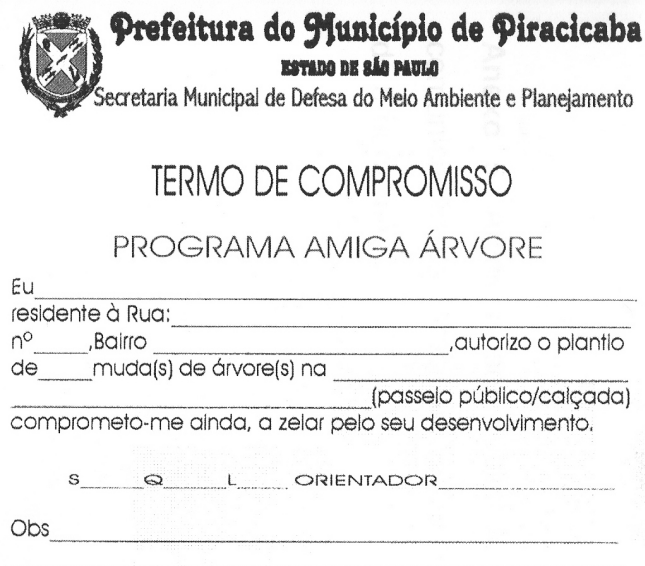

Piracicaba de 2001

Figura 1. Folder explicativo e Termo de Compromisso entregues ao morador no Programa Amiga Árvore. 
O trabalho foi conduzido por uma equipe composta por um Engenheiro Agrônomo na coordenação mais um funcionário da prefeitura que fiscalizava e orientava o plantio. A abertura dos berços, o transporte das mudas e o plantio eram feitos com pessoal específico para estas finalidades: quatro funcionários que abriam canteiros, transportavam e plantavam as mudas e um motorista de caminhão. O trabalho de campo, com o levantamento dos locais potenciais e da coleta de autorizações de plantio foi realizado por estagiários estudantes de Engenharia Florestal da Escola Superior de Agricultura "Luiz de Queiroz". Em algumas etapas, contou-se com o auxílio de jovens do SEAME (Serviço de Apoio ao Menor), através do Programa Agente Jovem, no qual adolescentes, na faixa de 15 a 17 anos, atuavam diretamente na coleta de autorizações e também no plantio, de maneira a integrálos na Comunidade e, assim, prepará-los para trabalhos sócio-ambientais. Os jovens que realizaram este trabalho moravam nos bairros que receberiam a arborização e conheciam os moradores, fato tido como de fundamental importância para alcançar a concretização do objetivo proposto.

\section{RESULTADOS E DISCUSSÃO}

Este trabalho possibilitou o plantio de 420 indivíduos em 2 meses, utilizando 23 espécies (Tabela 1). 
Tabela 1 - Espécies utilizadas nos bairros atendidos pelo Programa Amiga Árvore, Piracicaba, SP.

\begin{tabular}{|c|c|c|}
\hline Nome comum & Nome científico & Porte \\
\hline Acerola & Malpighia emarginata Sessé \& Moc. ex. DC. ${ }^{\star \star *}$ & Arbustivo \\
\hline Chapéu de napoleão & Thevetia peruviana (Pers.) K. Schum. ${ }^{* *}$ & Arbustivo \\
\hline Cróton & Codiaeum variegatum (L.) A. Juss. ** & Arbustivo \\
\hline Espirradeira & Nerium oleander L. ${ }^{\star \star \star}$ & Arbustivo \\
\hline Falsa murta & Murraya exotica L. ${ }^{* * *}$ & Arbustivo \\
\hline Flamboyant mirim & Caesalpinia pulcherrima (L.) Sw. ${ }^{* *}$ & Arbustivo \\
\hline Grevílea anã & Grevillea banksii R. Br. ${ }^{* \star *}$ & Arbustivo \\
\hline Resedá & Lagerstroemia indica $\mathrm{L}^{* *}$ & Arbustivo \\
\hline Araçá & Psidium cattleyanum Sabine* & Pequeno \\
\hline Aroeira pimenteira & Schinus terebinthifolius Raddi ${ }^{* * *}$ & Pequeno \\
\hline Ipê amarelo & $\begin{array}{l}\text { Tabebuia chrysotricha (Mart. ex A. DC.) } \\
\text { Standl..** }\end{array}$ & Pequeno \\
\hline Pitanga & Eugenia uniflora L. ${ }^{* *}$ & Pequeno \\
\hline $\begin{array}{l}\text { Cerejeira (mini- } \\
\text { jambo-rosa, lili-pili) }\end{array}$ & Achmena smithii (Poir.) Merr. \& Perry ${ }^{\star \star *}$ & $\begin{array}{l}\text { Pequeno- } \\
\text { Médio }\end{array}$ \\
\hline Aroeira salsa & Schinus molle L..** & Médio \\
\hline Ipê branco & Tabebuia roseo alba (Ridl.) Sandwith* & Médio \\
\hline Canelinha & Nectandra megapotamica (Spreng.) Mez ${ }^{* * *}$ & Médio-Grande \\
\hline Genipapo & Genipa americana L.* & Médio-Grande \\
\hline Magnólia amarela & Michelia champaca L. ${ }^{* *}$ & Médio-Grande \\
\hline Pau viola & Cytharexillum myrianthum Cham. ${ }^{*}$ & Médio-Grande \\
\hline Ingá & Inga edulis Mart. ${ }^{*}$ & Grande \\
\hline Jambolão & Syzygium cumini (L.) Skeels* & Grande \\
\hline Mirindiba rosa & Lafoensia glyptocarpa Koehne* & Grande \\
\hline Oiti & Licania tomentosa (Benth.) Fritsch ${ }^{\star \star \star}$ & Grande \\
\hline
\end{tabular}


No plantio viário realizado no Bairro Paineiras (Tabela 2), as três espécies mais significativas foram a canelinha (médio-grande porte), com 24 indivíduos, a falsa murta (porte arbustivo), com 33, e a espirradeira (porte arbustivo), com 18. O número de espécies de porte arbustivo ou pequeno utilizado nesse bairro foi de 9 , com 81 indivíduos plantados no total, enquanto que o de espécies de médio ou grande porte totalizou 3 , com 33 indivíduos. No Bairro Paulista, as espécies plantadas totalizaram 3 (20 indivíduos no total), sendo 2 de porte arbustivo ( 7 espirradeiras e 2 falsa murtas) e 1 de porte médio-grande (11 indivíduos de canelinha). No Bairro Balbo foi plantada 1 única espécie (2 indivíduos de grevílea anã). O total plantado na arborização viária nestes bairros foi de 136 indivíduos, divididos em 9 espécies de porte arbustivo ou pequeno (92 indivíduos) e 3 médio-grande (47 indivíduos).

Tabela 2 - Quantidade de indivíduos plantados, por espécie, na arborização viária dos bairros atendidos pelo Programa Amiga Árvore, Piracicaba, SP.

\begin{tabular}{|l|c|c|c|}
\hline \multirow{2}{*}{ Nome comum } & \multicolumn{3}{|c|}{ Bairro } \\
\cline { 2 - 4 } & Paineiras & Paulista & Balbo \\
\hline Canelinha & 24 & 11 & - \\
\hline Falsa murta & 33 & 2 & - \\
\hline Espirradeira & 18 & 7 & - \\
\hline Grevílea anã & 11 & - & 2 \\
\hline Flamboyant-mirim & 8 & - & - \\
\hline Cróton & 7 & - & - \\
\hline Oiti & 5 & - & - \\
\hline Magnólia Amarela & 4 & - & - \\
\hline Pitanga & 1 & - & - \\
\hline Chapéu de napoleão & 1 & - & - \\
\hline Ipê Amarelo & 1 & - & - \\
\hline Acerola & 1 & - & - \\
\hline Total & 114 & 20 & 2 \\
\hline Total Geral & & 136 & \\
\hline
\end{tabular}

Nas áreas verdes do Bairro Paineiras (Tabela 3), das 4 espécies com mais indivíduos plantados, 2 foram de arbustivas, divididas entre 12 espirradeiras, 8 falsas murtas e, 2 de médio ou grande porte, compostas por 14 canelinhas e 5 oitis. O número de 
espécies de médio-grande porte totalizou 6 (39 indivíduos) e o de porte arbustivo ou pequeno, 8 espécies (44 indivíduos). No Bairro Piracicamirim o número de espécies utilizado na arborização viária de áreas verdes totalizou 6 (25 indivíduos no total), divididas em 5 espécies de médio-grande porte (23 indivíduos) e 1 de pequeno porte (2 indivíduos).

Tabela 3 - Quantidade de indivíduos plantados no mês de agosto de 2002, por espécie, em áreas verdes, dos bairros atendidos pelo Programa Amiga Árvore, Piracicaba, SP.

\begin{tabular}{|l|c|c|}
\hline \multirow{2}{*}{ Nome comum } & \multicolumn{2}{|c|}{ Bairro } \\
\cline { 2 - 3 } & Paineiras & Piracicamirim \\
\hline Canelinha & 14 & - \\
\hline Espirradeira & 12 & - \\
\hline Falsa murta & 8 & - \\
\hline Oiti & 5 & - \\
\hline Ipê Amarelo & 5 & 2 \\
\hline Ipê Branco & 5 & 3 \\
\hline Araçá & 5 & - \\
\hline Mirindiba & 5 & - \\
\hline Ingá & 5 & 5 \\
\hline Genipapo & 5 & 5 \\
\hline Cereja (mini jambo) & 5 & - \\
\hline Grevílea anã & 4 & - \\
\hline Acerola & 4 & - \\
\hline Jambolão & - & 5 \\
\hline Chapéu de napoleão & 1 & - \\
\hline Pau Viola & - & 5 \\
\hline Total & & \\
\hline Total geral & & \\
\hline
\end{tabular}

O plantio viário realizado no Bairro Costa Rica atingiu 12 espécies, sendo que das 4 mais plantadas destacaram-se 3 arbustivas ou de pequeno porte: espirradeira (41 indivíduos), pitanga (19 indivíduos) e falsa murta (16 indivíduos); e 1 espécie de médiogrande porte: canelinha (36 indivíduos). No Bairro Alvorada II foram plantadas 6 espirradeiras, no Alvorada III 3 espirradeiras, 2 falsas murtas e 5 canelinhas e no Água Branca, 1 falsa murta, 2 canelinhas e 2 resedás. O plantio viário totalizou 172 indivíduos 
(Tabela 4), divididos em 13 espécies, sendo 10 espécies de porte arbustivo ou pequeno (124 indivíduos) e 3 espécies de médio-grande porte (48 indivíduos).

Tabela 4 - Quantidade de indivíduos plantados, por espécie, na arborização viária dos bairros atendidos pelo Programa Amiga Árvore, Piracicaba, SP.

\begin{tabular}{|c|c|c|c|c|}
\hline \multirow{2}{*}{ Nome comum } & \multicolumn{4}{|c|}{ Bairro } \\
\hline & Costa Rica & Alvorada II & Alvorada III & Água Branca \\
\hline Espirradeira & 41 & 6 & 3 & - \\
\hline Canelinha & 36 & - & 5 & 2 \\
\hline Pitanga & 19 & - & - & - \\
\hline Falsa murta & 16 & - & 2 & 1 \\
\hline Ipê Amarelo & 12 & - & - & - \\
\hline Grevílea anã & 8 & - & - & - \\
\hline Cróton & 5 & - & - & - \\
\hline Aroeira pimenteira & 5 & - & - & - \\
\hline Aroeira salsa & 4 & - & - & - \\
\hline Cereja & 2 & - & - & - \\
\hline Acerola & 2 & - & - & - \\
\hline Oiti & 1 & - & - & - \\
\hline Resedá & - & - & - & 2 \\
\hline Total & 151 & 6 & 10 & 5 \\
\hline Total Geral & & & 172 & \\
\hline
\end{tabular}

O plantio em áreas verdes (Tabela 5) totalizou 4 indivíduos de ipê branco (médiogrande porte).

Tabela 5 - Quantidade de indivíduos plantados no mês de setembro de 2002, por espécie, em áreas verdes dos bairros atendidos pelo Programa Amiga Árvore, Piracicaba, SP.

\begin{tabular}{|l|c|c|c|c|}
\hline \multirow{2}{*}{ Nome comum } & \multicolumn{4}{|c|}{ Bairro } \\
\cline { 2 - 5 } & Costa Rica & Alvorada II & Alvorada III & Água Branca \\
\hline Ipê Branco & - & 4 & - & - \\
\hline Total Geral & \multicolumn{4}{|c|}{4} \\
\hline
\end{tabular}


No total geral, em arborização viária, plantou-se 420 indivíduos, de 23 espécies, distribuídas em 13 de porte arbustivo ou pequeno (252 indivíduos) e 10 de médio-grande porte (168 indivíduos), sendo que, destas, 66 foram plantadas em áreas verdes, reduzindo para 102 o total de árvores, de porte médio ou grande, plantado em frente às residências (Gráfico 1).

\section{Distribuição do plantio por espécie}

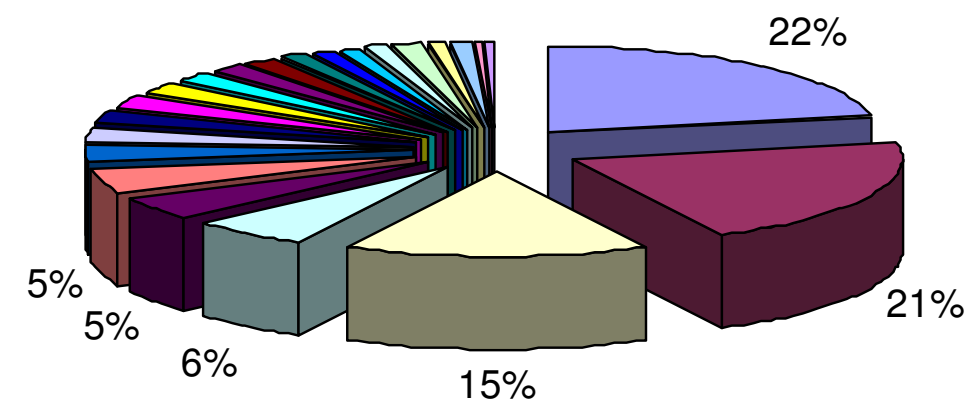

\begin{tabular}{|llll|}
\hline$\square$ Canelinha & $\square$ Espirradeira & $\square$ Falsa murta & $\square$ Grevílea anã \\
$\square$ lpê amarelo & $\square$ Pitanga & $\square$ Cróton & $\square$ lpê branco \\
$\square$ Oiti & $\square$ Genipapo & $\square$ Ingá & $\square$ Flamboyant mirim \\
$\square$ Acerola & $\square$ Cerejeira & $\square$ Araçá & $\square$ Aroeira pimenteira \\
$\square$ Jambolão & $\square$ Mirindiba rosa & $\square$ Pau viola & $\square$ Aroeira salsa \\
$\square$ Magnólia amarela & $\square$ Chapéu de napoleão & $\square$ Resedá & \\
\hline
\end{tabular}

Gráfico 1. Distribuição do plantio por espécie.

Nos plantios realizados pelo Programa Amiga Árvore, o número de espécies e de indivíduos arbustivos ou de pequeno porte utilizado foi maior (13 e 252, respectivamente) em detrimento das espécies de maior porte e de grande valor ambiental (10 e 168), sendo que, destas últimas, somente 102 indivíduos foram plantados em frente às residências.

Estes dados são preocupantes por demonstrarem o processo de "arbustificação" praticado na cidade de Piracicaba neste período; nota-se o predomínio do plantio de arbustos ou de árvores de pequeno porte em frente das residências (Gráfico 2). 


\section{Distribuição das espécies plantadas nas residências pelo porte}

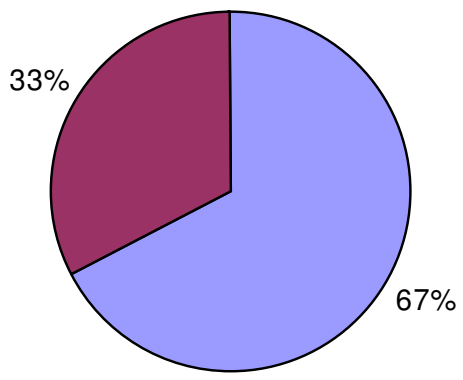

口 porte arbustivo ou pequeno

$\square$ médio ou grande porte

Gráfico 2. Distribuição das espécies plantadas nas residências por porte.

Mesmo no acompanhamento das vias de áreas verdes, onde poderiam ser utilizadas somente árvores de grande porte, optou-se, também, por indivíduos arbustivos e de pequeno porte (Gráfico 3).

\section{Distribuição das espécies plantadas nas áreas verdes pelo porte}

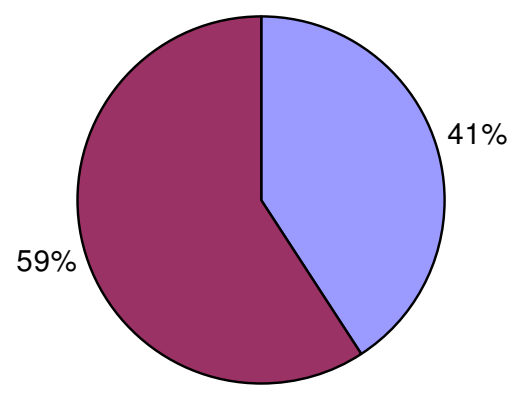

Gráfico 3. Distribuição das espécies plantadas no acompanhamento de vias de áreas verdes, por porte.

Até hoje, essas falhas continuam ocorrendo, demonstrando que acima da prioridade ecológico-ambiental na arborização, opta-se pelo mais "seguro" e menos "trabalhoso", ao utilizar-se portes arbóreos pequenos ou arbustos, que "não causam problemas" às calçadas, à fiação e ao morador, idéia totalmente errada e que deve ser combatida. Espécies como a falsa-murta, a espirradeira, o flamboyant-mirim, dentre outras, necessitam de podas constantes para ficarem com aspecto arbóreo e geram muitos gastos com manutenção além de, muitas vezes competirem com o munícipe pelo espaço das calçadas, formando verdadeiros bloqueios de visão e de passagem por suas copas baixas. No caso de plantio 
inadequado, algumas espécies arbustivas também podem danificar o calçamento; muitas, possuem madeiras moles e, facilmente quebráveis; outras, apresentam fatores indesejáveis como toxidez, princípios alérgenos ou espinhos. Estas espécies não produzem os benefícios ambientais que podem ser obtidos com a utilização das de maior porte, como o sombreamento e a grande evapotranspiração que, para uma cidade como Piracicaba, extremamente quente em meses de calor, seria o mais recomendado.

As espécies utilizadas no Programa foram muito semelhantes às divulgadas por empresas de distribuição de energia elétrica, que, atendendo a interesses particulares criaram o mito de incompatibilidade entre árvores de médio e grande porte com os sistemas de energia (MILANO; DALCIN, 2000). Com isso, vem sendo difundida a utilização de arbustos e árvores de pequeno porte nas vias públicas, o que contribui negativamente para alterar a visão do morador urbano sobre a utilização de árvores de maiores portes. É necessário romper com esse paradigma e, ao mesmo tempo, realizar um trabalho conjunto com estas empresas, visando à preocupação ambiental, às funções da arborização no ambiente urbano e à convivência pacífica entre os sistemas de energia e árvores de médio e grande porte. Os padrões de rede de energia podem e devem mudar. Algumas companhias do setor elétrico estão determinando o fim desse mito e, com dose de pioneirismo e boa vontade, a COPEL (Companhia Paranaense de Energia) e a LIGHT (RJ), vêm fazendo uso das redes compactas, melhorando significativamente a convivência entre as árvores e as redes, além de promover uma mudança radical no sistema de distribuição de energia e não na seleção, plantio e manejo das árvores (MILANO; DALCIN, 2000). A CEMIG (Companhia Energética de Minas Gerais) também realiza esforços nesse sentido.

As fiações de rede compacta e subterrânea deveriam ser priorizadas no município, porém, percebe-se a manutenção de um sistema obsoleto (rede convencional), que gera grande poluição visual e ainda obriga senão a supressão da planta, a mutilação constante das árvores, por meio da poda, mesmo com toda a problemática que resulta: redução da vida útil dos indivíduos, deformação das copas, desequilíbrios, quedas, problemas fitossanitários e redução dos benefícios ambientais.

Os conflitos entre árvores e redes elétricas aéreas, considerando-se os atuais sistemas de redes, são mais significativos e críticos para árvores de porte mediano, devido à forte coincidência entre a altura das árvores e das redes. Assim, há alta demanda de poda, resultando em árvores deformadas, morfologicamente descaracterizadas e fisiologicamente debilitadas. Embora nunca recomendadas pelos manuais defensores do mito que considera árvores e redes elétricas incompatíveis, árvores de grande porte podem e devem ser utilizadas sob redes, com restritos problemas e baixas demandas de poda (MILANO; DALCIN, 2000). As podas mal conduzidas e drásticas mutilam as árvores urbanas, ao preservar os serviços sem considerar, entretanto, que a árvore, também, oferece 
importantes contribuições à população. Portanto, é óbvia a conclusão de que políticas mais adequadas para preservar, tanto os serviços, quanto o vegetal, devam ser adotadas (PAIVA; GONÇALVES, 2002).

Velasco (2003), em sua dissertação, provou que é totalmente viável, financeiramente, a substituição de redes de distribuição de energia convencionais pelas compactas, devido a valores muito próximos de implantação de ambas, e da redução de $79,5 \%$ nos custos de manutenção da rede compacta, devido a fatores como a menor necessidade de poda. A autora também considerou melhoras significativas no aspecto geral da árvore devido à menor intervenção no vegetal, afirmando que a rede subterrânea, embora com custo de implantação aproximadamente 10 vezes maior quando comparado com o custo da convencional, já pode ser viável em diversas ocasiões devido ao seu reduzido custo de manutenção e alta confiabilidade do sistema elétrico; ainda cita que técnicas mais modernas de engenharia tendem a abaixar, significativamente, o custo de implantação do sistema. Para Paiva e Gonçalves (2002) redes elétricas protegidas permitem uma convivência pacífica com as árvores de grande porte e, onde elas ainda não são realidade, recomendam que podas direcionais permitam o desenvolvimento desses vegetais para que tenham condições de se desenvolver satisfatoriamente.

No presente trabalho, houve rejeição da população por árvores de maior porte, sendo identificada a necessidade de uma ampla campanha de educação ambiental, a fim de reverter este quadro, que prejudicará os futuros programas de arborização, na cidade; houve preferência dos moradores pelas espécies arbustivas.

O trabalho com os jovens do Projeto Agente Jovem, possibilitou a capacitação dos participantes para trabalhos sócio-ambientais e integrou-os à comunidade (Figuras 2, 3 e 4), permitindo um maior acesso do projeto aos bairros trabalhados, muitos deles residências das crianças e adolescentes atendidos por este Projeto.

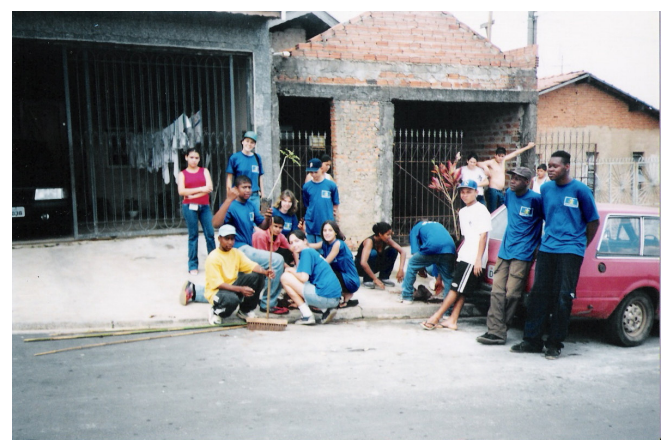

Figura 2. Crianças e adolescentes do Programa Agente Jovem

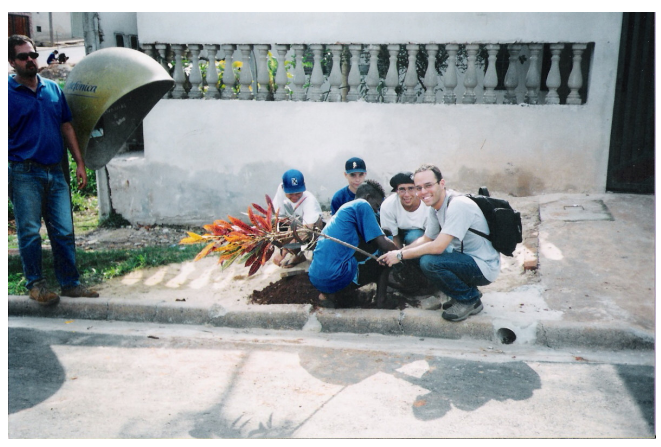

Figura 3. Plantio de mudas com os jovens participantes do Programa 


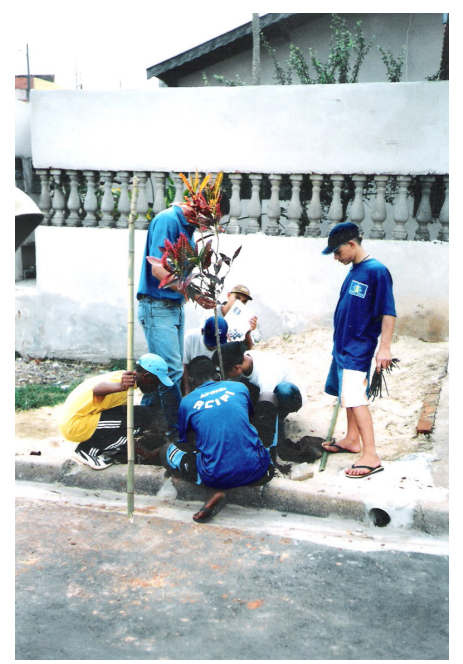

Figura 4. Plantio de mudas envolvendo os jovens e a comunidade.

\section{CONCLUSÕES}

Os benefícios ambientais proporcionados pela utilização de árvores de médio e grande porte serão reduzidos nos bairros de Piracicaba atendidos pelo Programa, ainda num futuro próximo, devido à priorização do plantio de arbustivas.

A preferência dos moradores pelas espécies arbustivas pode ser revertida através de intensa campanha de educação ambiental a fim de que, em outros programas de arborização futuros na cidade, seja alterado tal direcionamento. A participação dos adolescentes do Programa Agente Jovem, na coleta de autorizações de plantio, foi importante, embora, as coletas de autorizações de plantio e orientação de plantio de espécies devam ser feitas, prioritariamente, por técnicos capacitados, que podem, em seu trabalho, argumentar a favor da implantação e dos benefícios de árvores, aos cidadãos, não fazendo, apenas, um trabalho quantitativo.

O viveiro municipal deve interromper a produção de arbustos para arborização, focando sua produção em espécies mais significativas e da flora regional. O município tem que desenvolver políticas públicas que promovam a melhoria dos locais de plantio e das técnicas utilizadas, incentivando testes sobre o comportamento de algumas árvores no meio urbano para, finalmente implantar uma arborização decente e viável. Para isso, torna-se necessário melhorar os canteiros de plantio, ampliando suas dimensões, preparando adequadamente o solo do local, além de incrementar a área disponível para a planta, cuidando para que seu estabelecimento ocorra, de fato.

A inclusão em projetos (plantas baixas) da localização de tubulações de água, esgoto e gás no planejamento, tanto geral, quanto da arborização, além da adequação do sistema de distribuição de energia elétrica e iluminação pública são pontos de extrema 
importância a serem considerados, para permitir o plantio de espécies maiores, que possam contribuir, positivamente, para a melhoria ambiental e estética da cidade.

Sempre, um correto planejamento urbano é fundamental para a compatibilização da presença de árvores de maior porte com os equipamentos públicos e áreas construídas; em áreas já consolidadas, é possível a elaboração de alternativas de desenho urbano para adaptar essa deficiência e reduzir custos de implantação.

\section{AGRADECIMENTOS}

Os autores agradecem a todos que participaram do Programa, à Arlet Maria de Almeida, José A. Pereira, Mirene Ferreira, Cristine Kaori Suemasu, Sabrina Satie Pacheco Motoshima, Márcio Amaral Yamamoto, Ana Luiza de Campos Paula, Maurício, Gisele Lambertucci, ao pessoal do plantio, aos adolescentes do Programa Agente Jovem e seus coordenadores, por todo esforço realizado na tentativa de melhorar a arborização em Piracicaba e na busca por mais qualidade de vida para seus cidadãos.

\section{REFERÊNCIAS BIBLIOGRÁFICAS}

GREY, G.W.; DENEKE, F.J. Urban forestry. New York, John Wiley, 1978, 279p.

INSTITUTO BRASILEIRO DE GEOGRAFIA E ESTATÍSTICA - IBGE. Disponível em $<$ http://www.ibge.gov.br>. Acesso em: 2 de abr. 2007.

LIMA, A.M.L.P. PIRACICABA/SP: Análise da arborização viária na área central e seu entorno. 1993, 238p. Tese (Doutorado em Solos e Nutrição de Plantas) - Escola Superior de Agricultura “Luiz de Queiroz”, Universidade de São Paulo, Piracicaba, 1993.

LOMBARDO, M.A. Ilha de calor nas metrópoles: o exemplo de São Paulo. São Paulo: HUCITEC, 1985, 244p.

LORENZI, H. Árvores Brasileiras. Manual de identificação e cultivo de plantas arbóreas nativas do Brasil. Nova Odessa: Editora Plantarum, 2000, v.1, 352p.

LORENZI, H.; BACHER, L.B.; LACERDA, M.; SARTORI, S. Frutas brasileiras e exóticas cultivadas (de consumo in natura). Nova Odessa: Editora Plantarum, 2006, v.1, 674p.

LORENZI, H.; SOUZA, H.M.; TORRES, M.A.V.; BACHER, L.B. Árvores Exóticas no Brasil: madeireiras, ornamentais e aromáticas. Nova Odessa: Editora Plantarum, 2003, v.1, 384p. 
MASCARÓ, L; MASCARÓ, J. Vegetação urbana. 2.ed. Porto Alegre: Mais Quatro Editora, 2005. 204 p.

MCPHERSON, E.G., MUCHNICK, J. Effects of street tree shade on asphalt concrete pavement performance. Arboriculture and Urban Forestry, v.6, n.31, p. 303-310, nov. 2005.

MENEGHETTI, G.I.P. Estudo de dois métodos de amostragem para inventário da arborização de ruas dos bairros da orla marítima do município de Santos, SP. 2003, 100p. Dissertação (Mestrado em Ciências Florestais) - Escola Superior de Agricultura "Luiz de Queiroz", Universidade de São Paulo, Piracicaba, 2003.

MILANO, M., DALCIN, E. Arborização de vias públicas. Rio de Janeiro: Light, 2000, 226p.

MISSOURI BOTANICAL GARDEN - MOBOT. Disponível em $<$ http://mobot.mobot.org/W3T/Search/vast.html>. Acesso em 4 de abr. 2007.

PAIVA, H.N.D.; GONÇALVES, W. Florestas Urbanas: planejamento para melhoria da qualidade de vida. Viçosa: Aprenda Fácil Editora, 2002, v.2, 180p.

SEITZ, R.A. A avaliação visual das árvores de risco. Revista Ação Ambiental, Viçosa, v. 8, n. 33, p. 15-20, set./out. 2005.

SILVA FILHO, D.F. Aplicação de videografia aérea multispectral na avaliação de floresta urbana. 2004, 88p. Tese (Doutorado em Produção Vegetal) - Universidade Estadual "Julio de Mesquita Filho" - Faculdade de Ciências Agrárias e Veterinárias Campus de Jaboticabal, Jaboticabal, 2004.

SILVA FILHO, D.F. - Disponível em <http://www.esalq.usp.br/destaques.php?id=208\#>. Acesso em: 20 de abr. 2007.

SILVA FILHO, D.F. Sombra também gera economia. Gazeta de Piracicaba, Piracicaba, 21 set. 2006. Dia da Árvore, p.9.

SILVA, L.F. Situação da arborização viária em dois bairros de Americana e proposta de espécies nos bairros Antônio Zanaga I e II. 2005, 80p. Dissertação (Mestrado em Fitotecnia) - Escola Superior de Agricultura "Luiz de Queiroz", Universidade de São Paulo, Piracicaba, 2005. 
STRINGHETA, A.C.O. Arborização urbana no Brasil. Revista Ação Ambiental, Viçosa, v. 8, n. 33, p. 9-11, set./out. 2005.

VELASCO, G.D.N. Arborização viária x sistemas de distribuição de energia elétrica: avaliação dos custos, estudo das podas e levantamento de problemas fitotécnicos. 2003, 94p. Dissertação (Mestrado em Fitotecnia) - Escola Superior de Agricultura "Luiz de Queiroz", Universidade de São Paulo, Piracicaba, 2003. 